\title{
«Entiendes de exégesis menos de lo deseable». La Escritura en la obra de Karl Rahner
}

\author{
Carlos Schickendantz \\ CENTRO TEOLÓGICO MANUEL LARRAÍN
}

«Entiendes de exégesis menos de lo deseable». Son palabras que Rahner se aplica también a sí mismo y expresan su modestia, o más exactamente, la relativización de sí mismo de la que habla a menudo, su autocrítica, también su ironía ${ }^{1}$. Pero ellas expresan además un problema en la obra de Rahner: se trataría de un sistema especulativo con poco trabajo bíblico e histórico. Un análisis más o menos detallado, como el que afronta esta contribución, dejará a la luz que tal opinión está necesitada de matices.

En 2001, al publicar su muy buena tesis doctoral, Günther Wassilowsky ha hablado de «una nueva época en el tratamiento de la obra de Rahner ${ }^{2}$. Para explicar su afirmación, el autor cita allí diversos trabajos $^{3}$. Hoy podrían añadirse otros más ${ }^{4}$. Ahora bien, ¿qué caracteriza esta «nueva época», a juicio de Wassilowsky? Investigaciones que prestan atención al contexto biográfico y al proceso de formación de los textos, que ponen de relieve, particularmente, la importancia y los contenidos de la

1 Cf. «Exegese und Dogmatik», en Schriften zur Theologie. Bd. 5. Neuere Schriften (Einsiedeln 1962), 82-111, 93.

2 Universales Heilssakrament Kirche. Karl Rahners Beitrag zur Ekklesiologie des II. Vatikanums (Innsbruck 2001), 106.

3 A. Zahlauer, Karl Rahner und sein "produktives Vorbild" Ignatius von Loyola (Innsbruck 1996); P. Rulands, Menschsein unter dem An-spruch der Gnade. Das übernatürliche Existential und der Begriff der natura pura bei Karl Rahner (Innsbruck 2000); W. Schmolly, Eschatologische Hoffnung in Geschichte. Karl Rahners Grundverständnis der Kirche als theologische Begleitung von deren Selbstvollzug (Innsbruck 2001).

4 Cf., por ejemplo, J. Kiтtel, Kirche als Ereignis. Ein Beitrag zur Grundlegung des sakramentalen Kirchenbegriffs im ekklesiologischen Entwurf von Karl Rahner (Freiburg i.Br. 2010). 
fase inicial de la teología de Rahner; fase que, a su vez, ofrece una más adecuada y justa mirada de conjunto de su obra y que contextualiza mejor algunas de las críticas existentes sobre el trabajo del teólogo alemán. Esta perspectiva fundamental, es claro, se enmarca en una tendencia más general: «el significado del contexto, de la biografía de aquel que hace teología se ha visto fortalecido y exigido en tiempo reciente» ${ }^{5}$.

Ahora bien, también los estudios bíblicos tienen una historia rica y compleja en el catolicismo del siglo XX. Un análisis más detallado del asunto que nos ocupa debería prestar atención al estado de la cuestión en cada tema que Rahner aborda, precisamente en el momento del tratamiento que el teólogo alemán hace de él. En algunos puntos de mi contribución podrá observarse más explícitamente cómo Rahner ha sufrido el influjo, por una parte, y contribuido, por otra, al desarrollo de dichos estudios. Lo que es evidente para el estudio de todos los autores, lo es también para Rahner: se lo valora con mayor exactitud, sus aportes y sus limitaciones, si se presta atención al contexto en el que su teología fue elaborada y escrita. Un ejemplo que visibiliza un dato importante: la situación de la exégesis católica mejoró sustancial, aunque progresivamente, como es generalmente reconocido, con la publicación de la encíclica Divino afflante Spiritu de noviembre de 1943; entonces, Rahner estaba a punto de cumplir cuarenta años y, en buena medida, estaba decidida ya la columna vertebral de su teología. Reconozco aquí, al mismo tiempo que, el conocido reproche (la teología de Rahner no es bíblica o la Biblia no encuentra allí su lugar fundante), que en diversas ocasiones autores rahnerianos se han visto invitados a responder, determinó el punto de vista de mi análisis. En lo que sigue, ofrezco un panorama en orden genético que, en principio, pretende no dejar fuera de consideración ninguno de los principales trabajos de Rahner sobre el asunto. Con dos excepciones, por razones de espacio: por una parte, publico por separado un análisis del material que Rahner elaboró al inicio del Concilio en torno a la discusión del esquema preparatorio, De fontibus revelationis, juntamente con su artículo de 1963, «Escritura y Tradición», referido a la misma temática ${ }^{6}$. Por otra, también dejo fuera aquí el tratamiento

5 A. Batlogg, Die Mysterien des Lebens Jesu bei Karl Rahner. Zugang zum Christusglauben (Innsbruck 2001), 52.

6 Cf. C. Schickendantz, «Escritura y Tradición. Karl Rahner en el "primer conflicto doctrinal” del Vaticano II», Teología 106 (2011) en edición. 
de la obra, "Curso fundamental sobre la fe» que, aunque es una obra importante en el autor, no refleja un problema específico en relación a la Escritura que no pueda verificarse en las demás obras sistemáticas de Rahner. A este texto le he dedicado ya un análisis detenido?

\section{Los AÑos de Formación teológica -VAlKenburg (Holanda), I929- 1933 - «NO HAY HUELLA»}

Siquiera brevemente afronto, ante todo, los primeros años de formación y estudio extrayendo algunas ideas referidas a nuestra tema. ¿Con quiénes estudió Rahner y dónde? ¿Cuáles fueron sus primeras producciones en relación a la Biblia? Después de estudiar filosofía, un año en Feldkirch/Tisis, Austria, y dos en Pullach, cerca de Munich, Rahner comenzó sus estudios teológicos en el otoño de 1929 en Valkenburg, Holanda. Luego de rendir el examen complexivo cerró sus estudios en julio de 1933. Muchos años después, él mismo se ha referido a aquel instituto en términos relativamente favorables, comparándolo con otros lugares. Para adquirir un conocimiento más acabado de Rahner, debería concretarse una tarea aún no realizada, constata Neufeld: prestar atención, precisamente, a los contenidos de la formación intelectual, a los diversos manuales usados por sus profesores ${ }^{8}$. Los exégetas que enumera Neufeld son Augustinus Merk, S.J., ${ }^{9}$ y, luego de su llamada a Roma, al Instituto Biblicum, G. Hartmann, y, sobre el AT en particular, a Albert Rembold

7 Cf. C. Schickendantz, «El "Curso fundamental de la fe" de Karl Rahner. Objetivo, génesis y significado de un "experimento"», Teología y Vida 45 (2004), 137-156. ¿Qué evaluación puede hacerse en relación a la Escritura en esta obra publicada en 1976? La respuesta puede orientarse a partir de dos constataciones. Primero, no debe opacarse un aspecto determinante en la configuración de este libro: lo que Rahner llama el «primer nivel de reflexión». El Curso fundamental contiene solo el primer nivel. No constituye una sistemática teológica integral. Por otra, debe advertirse que, aunque puede ser considerado justamente como el trabajo más integral de su pensamiento, el Curso fundamental no representa una síntesis de su teología. En este sentido, puede decirse que las observaciones generales que se hacen al lugar de la Escritura en la obra de Rahner, encuentran en este texto una concreción peculiar, pero no novedosa.

8 K.-H. Neufeld, "Die Schrift in der Theologie Karl Rahners», Jahrbuch biblische Theologie 2 (1987), 229-246.

9 A quien Rahner cita dos veces en su tesis doctoral de 1936. Cf. más abajo. 
(1876-1933) ${ }^{10}$. La evaluación de Neufeld es lapidaria: no puede decirse que hayan dejado huella en Rahner, a partir de algo que pueda deducirse de lo expresado por él ${ }^{11}$. Distinta ha sido la situación en relación a Hermann Lange, que fue prefecto de estudio en aquel momento y, más importante, profesor del tratado que Rahner luego, en 1938, asumiría en Innsbruck utilizando su manual: el De gratia. De allí que Rahner se haya referido a él en diversas circunstancias, aunque no específicamente en relación al tema bíblico ${ }^{12}$.

Interesante para conocer las lecturas de Rahner en aquel período de su vida es el listado bibliográfico suyo que, con el título de «Valkenburg 1929/30", ha permanecido inédito ${ }^{13}$. Allí se advierte la cantidad de lecturas, «sorprendente» dice Neufeld ${ }^{14}$; muchos libros de patrística, espiritualidad, también sobre historia de la filosofía y, en particular, sobre el tema de la confesión y de la conversión que tendrán una larga historia en su obra, comenzando por el artículo publicado en $1934^{15}$. La bibliografía de estos años muestra algunas de las principales preocupaciones de Rahner, todavía lejos de los trabajos filosóficos publicados en 1939 y 1941, cuya atención exclusiva condujo a algunos a hablar equivocadamente de una primera fase filosófica en su obra ${ }^{16}$. A primera vista,

10 A. Rembold, S.J. (Übersetzt von -, Sinngemäss gedruckt von J.B.Gülich S.J.), Der Davidpsalter des Römischen Breviers - lateinisch und deutsch (auf Grund der ältesten Befunde des biblischen Textes und im Einklang mit den Besserungsvorschlägen katholischer Exegeten wiederhhergestellt), Valkenburg, Ignatiuskolleg, 1931, 204 pp.

11 K.-H. Neufeld, Die Brüder Rahner. Eine Biographie (Freiburg i.Br. 1994), 95.

12 Cf. K. Rahner, Glaube in winterlicher Zeit (Düsseldorf 1986), 51, 58ss.

13 Cf. K.-H.Neufeld, Die Brüder Rahner, 100ss. Neufeld da cuenta, también, sin citar el archivo, de un listado de lecturas en los años de su trabajo práctico, ordinario entre los jesuitas entre el tiempo de la formación filosófica y teológica. Rahner impartió clases de griego, latín y alemán para novicios en Tisis entre 1927 y 1929. Uno de los grupos de lectura: «Comentarios bíblicos de escritos del Nuevo Testamento y literatura complementaria con un claro punto central en los escritos paulinos», K.-H.Neufeld, Die Brüder Rahner, 87.

14 K.-H.Neufeld, Die Brüder Rahner, 99.

15 «Vom Sinn der häufigen Andachtsbeicht», Zeitschrift für Aszese und Mystik 9 (1934), 323-336 (asumido en Schriften zur Theologie. Bd. 3, 211-225 y, finalmente, en Sämtliche Werke. Bd. 11, 401-411).

16 Cf. algunos, "Le début d'une doctrine des cinq sens spirituels chez Origène», Revue d'Ascétique et de Mystique 13 (1932), 113-145; «Die geistliche Lehre des Evagrius Ponti- 
en aquel momento no se advierte una particular atención por el tema bíblico. Sí se ha producido ya un encuentro fundamental en la biografía intelectual del autor: el descubrimiento del libro de Joseph Maréchal en los años de Pullach que testifica el texto hasta hace poco inédito; corresponde a una traducción/resumen que el joven Rahner hizo de uno de los cuadernos de la obra de Maréchal, Point de départ de la metaphysique; se trata del tomo quinto publicado en 1926, Le thomisme devant la philosophie critique que mereció la especial atención de Rahner ${ }^{17}$. Destinado a enseñar historia de la filosofía de los siglos XVI y XVII en Pullach/ Munich, y después de realizar en Austria la tercera probación, K. Rahner va, a fines de 1934, a estudiar a Friburgo, Alemania; porque se trataba de un ramo histórico se prefirió una universidad alemana a Roma.

2. «E latere Christi» (I936) y "Ascesis y mística eN la patrística» (I939) - UN MODO DE TRABAJO TEOLÓGICO

A diferencia de lo originalmente planificado, cerca del término de sus estudios en Friburgo, habiendo ya entregado su borrador de tesis doctoral en filosofía a su director, M. Honecker, en mayo de 1936, Rahner es destinado a dar clases de teología en Innsbruck debido a vacantes que se habían producido allí. Rahner llega a Innsbruck en el verano de 1936 y, dos semanas después de su arribo, el 15 de julio, presenta su trabajo doctoral en teología con el título: E latere Christi. Der Ursprung der Kirche als zweiter Eva aus der Seite Christi, des zweiten Adam. Eine Untersuchung über den typologischen Sinn von Jo 19,34. El texto de 136 páginas mecanografiadas, hasta tiempo reciente ha pasado inadvertido en la bibliografía secundaria; fue publicado por primera vez en $1999^{18}$. Es verdad que el mismo Rahner, muchos años después, a diferencia del propio juicio positivo sobre su tesis en filosofía (Geist in Welt), se expresó despectivamente sobre él: reconoce haber «fabricado una disertación teológica pequeña, miserable, pero su-

cus. In ihren Grundzügen dargestellt», Zeitschrift für Aszese und Mystik 8 (1933) 21-38; "Der Begriff der ecstasis bei Bonaventura», Zeitschrift für Aszese und Mystik 9 (1934) 1-19; "Coeur de Jésus" chez Origène?», Revue d'Ascétique et de Mystique 15 (1934) 171-174.

17 Cf. «Die Grundlagen einer Erkenntnistheorie bei Joseph Maréchal», en Karl Rahner. Sämtliche Werke. Bd 2. Geist in Welt. Philosophische Schriften (Solothurn-DüsseldorfFreiburg i.Br. 1996), 373-406.

18 En Karl Rahner. Sämtliche Werke. Bd. 3. Spiritualität und Theologie der Kirchenväter (Düsseldorf - Freiburg i.Br. 1999), 1-84. 
ficiente para las medidas de entonces ${ }^{19}$. Es claro hoy que la preparación de dicho trabajo se remonta a sus años de estudio en Valkenburg; así lo testifica un manuscrito existente en el Rahner-Archiv y una carta que, con fecha 13 de junio de 1930, le escribe Karl a su hermano Hugo, en aquel momento a punto de entregar su tesis doctoral en Innsbruck, solicitándole que le envíe todo el material posible sobre este tema precisamente, «Ecclesia ex latere Christi» $^{20}$.

Un punto que parece llamativo es que este texto, E latere Christi, sea destacado, incluso por rahnerianos reconocidos, solo desde la perspectiva patrística o eclesiológica, lo cual es parcialmente correcto $^{21}$, cuando refleja también un trabajo bíblico, breve pero peculiar, en la bibliografía de Rahner de aquellos años. A este respecto, resulta interesante constatar que el primer lector de la tesis, y el único que escribió un informe, fuera precisamente un biblista, Paul Gächter, el 13 de septiembre de 1936. El profesor de dogmática, Franz Mitzka, firmó, sin añadir nada, el breve informe presentado por Gächter, seis días después. Su frase central reza: «El presente trabajo no solo es apropiado para una disertación doctoral, según las actuales normas válidas en esta Facultad de teología, sino que va más allá del promedio de tales trabajos y está enteramente maduro para su impresión $»^{22}$.

El objeto del trabajo doctoral es analizar «la historia de esa representación»: el origen de la Iglesia como segunda Eva a partir del costado

19 «Gnade als Mitte menschlicher Existenz. Ein Gespräch mit und über Karl Rahner aus Anlaß seines 70. Geburtstages», Herder-Korrespondenz 28 (1974) 77-92, 79s. (ahora en Sämtliche Werke. Bd. 25, 3-32).

20 Cf. K. H. Neufeld, «Unter Brüdern. Zur Frühgeschichte der Theologie K. Rahners aus der Zusammenarbeit mit H. Rahner», en H. Vorgrimler (ed.), Wagnis Theologie. Erfahrungen mit der Theologie Karl Rahners (Freiburg i. Br. 1979) 341354, 342 .

21 Ambas perspectivas merecerían un detenido análisis para una mejor comprensión de Rahner. Debería valorarse, por ejemplo, lo que significa en aquel momento esta presentación eclesiológica que va más allá de los planteos neoescolásticos y de la autocomprensión de la Iglesia como societas perfecta; el texto representaría «la intención original de la eclesiología de Rahner en el modo de la imagen (bildhaft)», W. Schmolly, Eschatologische Hoffnung in Geschichte, 34.

22 Citado en A. Batlogg, «Editionsbericht. Teil A. E latere Christi», en Sämtliche Werke. Bd. 3, XVII-XLIII, XX. Cf. también, A. BATlogG, "Karl Rahners theologische Dissertation "E latere Christi". Zur Genese eines patristischen Projekts (1936)", Zeitschrift für katholische Theologie 126 (2004) 111-130. 
herido de Cristo, el segundo Adán. El primer capítulo afronta el tema de los "fundamentos bíblicos»; el autor aborda allí, primero, la teología paulina y, luego, la joánica. En orden a nuestro tema pueden destacarse en la tesis, al menos, dos aspectos: el análisis que el autor hace de la

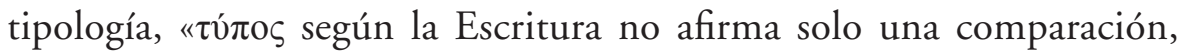
o un ejemplo... sino una profecía real querida por Dios», implica una "semejanza o una conformidad relativa», también un «acontecimiento neotestamentario como "cumplimiento" ${ }^{23} \mathrm{y}$, segundo, tratándose de un trabajo «inicialmente exegético», pero cuya «representación no se enseña en la Escritura con palabras claras», la tesis se orienta a analizar los testimonios siguientes al Nuevo Testamento. «Esta historia mostrará, mirando hacia atrás, que dicha representación sin duda pertenece al pensamiento del tiempo apostólico... que no es una mera conclusión del pensamiento del Nuevo Testamento, sino una parte de aquella teología apostólica, a partir de la cual han surgido los escritos joáneos, como un pensamiento que Juan quiso sugerir a sus lectores» ${ }^{24}$. En otros términos, de esto se trata: "cómo se utiliza metodológicamente en la literatura", esto es, "que una obra literaria se comprende a partir de un mundo de pensamiento diverso al del que fue escrito", en términos teológicos se concibe que "la "tradición", no aparece solo como norma dogmática externa de la exégesis, sino como un momento intrínseco de su propio método» ${ }^{25}$. La actualidad de esta problemática, bajo diversas perspectivas, no puede desconocerse.

Este tipo de enfoque se encuentra en otra obra temprana de Rahner: Aszese und Mystik in der Väterzeit. Ein Abriß, publicada simultáneamente con Geist in Welt en 1939. Se trata de una traducción, la única como libro en toda la obra de Rahner, y reelaboración de la obra de M. Viller, La spiritualité des premiers siècles chrétiens, publicada en París en 1930. Fue concebido originalmente por Rahner como un libro de estudio que ofrecía a los alumnos una síntesis de la espiritualidad patrística. La edición alemana es considerablemente distinta a la primera edición francesa, sea en extensión, sea en relación a su contenido ${ }^{26}$. De allí que

\footnotetext{
23 «E latere Christi», 13 nota 9, 14.

24 «E latere Christi», 10.

25 «E latere Christi», 10-11.

26 Cf. K. Neufeld, «Vorwort zur Neuausgabe» en M. Viller - K. Rahner, Aszese und Mystik in der Väterzeit: ein Abriß der frühchristlichen Spiritualität (Freiburg i.Br. ${ }^{2} 1989$ )
} 
H. U. von Balthasar haya afirmado en su recensión, que se trata «en lo fundamental casi de una obra original» del traductor y que representa «la primera obra alemana sobre la materia, la más amplia y más confiable» ${ }^{27}$. El texto tiene 12 capítulos y abarca los más diversos temas que luego el mismo Rahner estudiará con detalle, años después: gracia y pecado, creación y redención, conocimiento y voluntad, vinculación y libertad, palabra y sacramento, el martirio, etc. «Su trabajo requería conocimientos en casi todos los ámbitos de la teología y de la vida cristiana y eclesial ${ }^{28}$. Fue realizada entre 1937 y 1938; el prólogo está firmado en junio de 1938. Comparado con el suceso que obtuvo Geist in Welt (el trabajo doctoral en filosofía, nunca concluido; 1939), esta obra patrística de Rahner ha pasado casi inadvertida. Ahora bien, si a la luz de ella se relee Geist in Welt, y no a la inversa, entonces adquiere esta última un acento diverso en su significado, opina K. Neufeld ${ }^{29}$. Además, si se tiene en cuenta también la tesis doctoral en teología de 1936 (de hecho hay un trabajo sobre el mismo material de la patrística), se comprende mejor la observación del mismo Neufeld, «no puede haber duda que, para Rahner, fue determinante en aquellos años un modo de trabajo teológico que Aszese und Mystik expresa ejemplarmente» ${ }^{30}$. En ese «modo de trabajo» debe situarse esta relación estrecha entre Escritura y Patrística. En

$9^{*}-16 * 11^{*}$. Se trata de una reedición, sin modificaciones, del texto de 1939 (ahora incluida en Sämtliche Werke. Bd. 3, 123-390).

27 Stimmen der Zeit 136 (1939), 334. Igualmente se expresa K. PrüMM, recens. «M. Viller und K. Rahner, Aszese und Mystik in der Väterzeit», Zeitschrift für katholische Theologie 64 (1940), 174. Cf. nuevas opiniones, E. Farrugia, «Editionsbericht. Teil C. Aszese und Mystik in der Väterzeit» en Sämtliche Werke. Bd. 3, XLIV-LXXIII, LX. Sobre el cambio de título, cf. E. Farrugia, «Editionsbericht. Teil C. Aszese und Mystik in der Väterzeit», LVII.

K. Neufeld, Die Brüder Rahner, 134.

En relación a Hörer des Wortes, cf. K. Neufeld, «Unter Brüdern», 352. tes y su primer libro publicado, Worte ins Schweigen (Innsbruck, Rauch, 1938), escrito en la misma época en que dicta las conferencias en Salzburgo (1937), ya había sido puesta de manifiesto por H. U. von BALTHASAR en recensión a Geist in Welt. Cf. Zeitschrift für katholische Theologie 63 (1939) 371-379, 378. Cf., también, K. Neufeld, "Worte ins Schweigen. Zum Erfahrenen GottesVersTÄNDNIS KARL RAHNERS", Zeitschrift für katholische Theologie 112 (1990) 427-436, que de manera especial subraya la relación temática de Hörer des Wortes con Worte ins Schweigen. La conexión entre ambas obras es significativa desde el título mismo. Cf. también, E. Farrugia, "Editionsbericht. Teil C», LXI-LXVII. En qué medida 
esta obra no aparece tematizada la vinculación, como pudo constatarse siquiera brevemente en la tesis doctoral, sino simplemente desarrollada en un tema concreto: la espiritualidad. El capítulo primero, de los doce, está dedicado al «Nuevo Testamento y los primeros escritores cristianos». Un análisis más detallado podría mostrar el nivel de información y actualidad, según las medidas de entonces, que ofrecen tantos las ideas bíblicas como la literatura correspondiente seleccionadas por Rahner. Es claro que aún ese capítulo prevalentemente bíblico, que desarrolla temas como el seguimiento, la renuncia, la conversión, etc., está plagado de citas patrísticas. En cualquier caso, en la recepción del autor es importante tener en cuenta este "modo de trabajo teológico» puesto que, por una parte, ha permanecido oculto para muchos lectores y aun estudiosos y, por otra, representa, también en la perspectiva de Verbum domini (VD 86), una preocupación actual.

3. «Theos en el Nuevo Testamento» (1942-I943) - Un tema de teoLOGÍA BÍBLICA

Unas consideraciones sobre un artículo de naturaleza poco común en la bibliografía de Rahner. El texto se remonta a dos conferencias sostenidas en Viena en 1942 y 1943. La primera, en noviembre de 1942, abordó la noción de "Dios en el Nuevo Testamento" (Theos-Begriff im Neuen Testament), la segunda, en el otoño de 1943, sobre «El concepto de Dios de la revelación» (Gottesbegriff der Offenbarung). La primera parte fue publicada ese mismo año; luego, el texto completo apareció por primera vez en $1950^{31}$. Se trata del texto de teología biblica más elaborado por Rahner. Allí refiere al extenso artículo Өeó zum Neuen Testament editado por G. Kittel, de sesenta páginas con tipografía pequeña, advierte Rahner. A. Raffelt destaca el uso de esta obra de origen protestante, algo de ninguna manera sobreentendido en aquel momento $^{32}$. Para el objetivo de esta contribución pueden destacarse dos

Hörer des Wortes representa una «idea central bíblica», según K. Neufeld, puede quedar abierto. Cf. "Die Schrift in der Theologie Karl Rahners», 238.

31 "Gott" als erste trinitarische Person im Neuen Testament», Zeitschrift für katholische Theologie 66 (1942), 71-88; "Theos im Neuen Testament [1. Teil]», Bijdragen 11 (1950), 212-236; "Theos im Neuen Testament [2. Teil]», Bijdragen 12 (1951), 2452 (recogido en Schriften zur Theologie. Bd. 1, 91-167, y en Sämtliche Werke. Bd. 4, 346-403).

32 Cf. A. RafFeLt, «Editionsbericht» en Sämtliche Werke. Bd. 4, XIII-XXXVIII, XXI. 
aspectos. Primero, la crítica que incluye a los manuales teológicos en uso: «quizás (el artículo) pueda ofrecer algún que otro estímulo para una mejor fundamentación bíblico-teológica de nuestros tratados dogmáticos "De Deo uno" al uso, que en la mayoría de los casos son mera filosofía adornados con un poco de Escritura»" ${ }^{33}$. En segundo lugar, la advertencia metodológica: se trata de un artículo de teología bíblica, por tanto, de una lectura creyente de «la Escritura dentro de la Iglesia». Este «a priori teológico», observa Rahner, "no tiene por qué perjudicar necesariamente su rectitud y exactitud históricas». Si como advierte en algunos autores, no se «explican reflejamente» los supuestos teológicos generales desde los cuales se aborda el estudio, se corre el peligro de "caer en una eisegesis en una tergiversación de la Escritura» ${ }^{34}$. La advertencia, que no entra más en detalle, indica conciencia del problema.

Por lo demás, una adecuada valoración del artículo, situado en el contexto de la década del 40, debería revisar con exactitud los textos que Rahner cita y alude y verificar así su aporte o presunta novedad. Indudablemente está en relación con temáticas de teología dogmática que ya preocupaban a Rahner: ante todo la teología de la gracia, la discusión acerca de las relaciones propias o apropiadas del agraciado con las personas trinitarias, etc. De hecho, una de las ideas centrales del artículo (cuando el NT usa la noción "Dios» refiere, salvo excepciones, al Padre) ${ }^{35}$, ha sido continuamente citado por los manuales teológicos posteriores. K. Neufeld lamenta que en las discusiones sobre el pensamiento trinitario de Rahner no se preste atención a este «intensivo estudio de la teología neotestamentaria», y que no se advierta que, sin este trasfondo, resultan incomprensibles categorías rahnerianas clave tales como Dios como misterio infinito o la autocomunicación de Dios mismo, etc. El mismo Neufeld destaca, sin añadir datos más precisos, que «durante los años de la guerra en Viena, Rahner estudió intensivamente cuestiones de teología bíblica» ${ }^{36}$. Es cierto que no es difícil presumir una vinculación, por ejemplo, entre este trabajo bastante extenso y detallado sobre el tema de Dios y su perspectiva acerca de la primacía de la gracia

\footnotetext{
33 «Theos im Neuen Testament», en Sämtliche Werke. Bd. 4, 346-403, 346 nota 1 (cursiva mía).

34 «Theos im Neuen Testament», 347.

35 Cf., especialmente, «Theos im Neuen Testament», 385ss.

36 K. H. Neufeld, «Die Schrift in der Theologie Karl Rahners», 240 nota 47.
} 
increada en la experiencia cristiana que Rahner acababa de afirmar con claridad en el reconocido artículo de $1939^{37}$; perspectiva que representó un verdadero aporte al tratamiento sobre la gracia en la teología católica del siglo XX, y también una contribución al diálogo ecuménico, sea con las iglesias nacidas de la Reforma, sea con el mundo ortodoxo-oriental.

4. «CALCEDONIA - ¿Fin o COMIENZO?» (I954) -Un ARTí́culo PROGRAMÁtico- La Biblia PUede decirnos algo más...

En 1954, con ocasión de un nuevo aniversario del Concilio de Calcedonia, Rahner escribió un artículo cuyo valor varios autores han destacado; fue considerado «de lado católico como el punto de partida de la renovación cristológica» ${ }^{38}$. En cualquier caso es indudable su importancia para el mismo itinerario rahneriano. E. Maurice afirma, como hipótesis central de su muy buen trabajo doctoral de 1990 con el título: L'Évolution de la pensée christologique de Karl Rahner (1934-1984): «Rahner encuentra aquí un proyecto que desarrollará las potencialidades toda su vida. Esta es la razón por la cual este artículo merece verdaderamente el nombre de programa ${ }^{39}$. En consideración al tema de la presente contribución, me detengo solo en la primera sección del mismo y, en particular, en las consideraciones metodológicas. Allí se expresa Rahner en estos términos:

¿Cómo hacemos teología bíblica en general, y en particular en la dogmática en orden a la cristología? ¿Es completamente temerario y totalmente injusto decir que, entre los católicos, los exégetas de oficio no hacen teología bíblica en este campo, y que los dogmáticos conocen o utilizan la Escritura solo lo necesario para probar las tesis cristológicas ya dadas de antemano en un canon tradicional? O, en caso de

37 "Zur scholastischen Begrifflichkeit der ungeschaffenen Gnade», Zeitschrift für katholische Theologie 63 (1939), 137-156 (recogido luego en Schriften zur Theologie. Bd. 1, 347-375).

38 E. Maurice, La christologie de Karl Rahner (Paris 1995), 71. Allí con múltiples citas de autores.

39 E. Maurice, La christologie de Karl Rahner, 82. Cf. mi evaluación de dicha obra, «La cristología de Karl Rahner. ¿Una cristología posmoderna?», Proyecto 42 (2002), 87-115. Como constaté allí, la calificación de programa al artículo de 1954 representa quizás la idea más repetida por Maurice; por una parte, "contiene en germen toda la evolución ulterior» (p. 236 en su obra), por otra, está estrechamente ligado al «período cronológico anterior» (p. 93). 
que la primera parte de la opinión resulte demasiado dura, ¿dónde influye de algún modo perceptible la teología bíblica actual -cuando se hace- en la construcción y el contenido de la cristología tradicional de escuela? ${ }^{40}$.

El «punto de partida» en el artículo en general, y de estas consideraciones particulares, es la «actual comprensión común de la teología, aquí de la cristología, tal como aparece en los libros de escuela actuales, en la concepción teológica generalizada..., en lo que realmente está en la conciencia teológica de hoy» ${ }^{41}$. Allí mismo Rahner expresa su limitación en relación a una información suficiente sobre la "teología actual", quiere evitar una "generalización injusta" o "caricatura" de la situación de la cristología y de sus necesarias tareas futuras.

El texto refleja la insatisfacción por lo constatado en la teología al uso y, más aún, la falta de conciencia suficiente de dicha teología sobre su carencia: "no se diga que propiamente en este campo más no es posible. Algo es posible, porque debe serlo, al tratarse de las riquezas inagotables de la presencia de Dios en nosotros..." ${ }^{\prime 2}$. ¿Acaso dicha teología condensa y sintetiza "todo lo que oímos en la Escritura acerca de Jesús... o de lo que podríamos oír" si nos dijéramos de nueva forma y palabras, lo que aún no ha entrado a formar parte de la teología de escuela? Darse por satisfechos, respondiendo afirmativamente, equivaldría a negar que "la Escritura es la fuente de verdad inagotable sobre Cristo. ¿Se percibe en nuestro trabajo cristológico esa convicción como una fuerza activa y una santa inquietud?”“3. Adviértase el esfuerzo que moviliza a Rahner: debe hacer frente a una "evidencia», la autosatisfacción de una teología de manuales de difícil renovación; "un sistema cerrado" ${ }^{44}$. Dos insuficien-

40 «Chalkedon - Ende oder Anfang?», en A. Grillmeier - H. Bacht (eds.), Das Konzil von Chalkedon (Würzburg 1954) Bd. 3, 3-49. Con un nuevo título, recogido luego: "Probleme der Christologie von heute», en Schriften zur Theologie. Bd. 1, 169-222, y finalmente, en Sämtliche Werke. Bd. 12, 261-301. Cito según esta última edición.

41 «Probleme der Christologie von heute», 263 (cursiva mía).

42 «Probleme der Christologie von heute», 266.

43 «Probleme der Christologie von heute», 266.

44 Cf. la breve pero aguda descripción de la metodología de esta «Denzinger-Theologie», como la denomina, en un importante artículo de 1970, fruto de una conferencia en Montreal, en el verano de 1969, «Überlegungen zur Methode der Theologie», en Schriften zur Theologie. Bd. 9 (Zürich 1970), 79-126, aquí 81-82. Cf. el trabajo entre nosotros, F. Berríos, «El método antropológico-trascendental de 
cias metodológicas son explicitadas. Por una parte, enfrenta un "prejuicio silencioso pero efectivo": solo en y con los conceptos elaborados por la patrística y la escolástica a partir de la filosofía griega puede existir precisión conceptual y densidad de formulación. De allí que advierta que valorará su tarea en este artículo solo el que admita que se puede "ampliar el instrumental conceptual tradicional de la teología científica", sin que por ello se acabe en palabrería o mera literatura piadosa ${ }^{45}$. En segundo lugar, advierte una concepción inadecuada de la relación entre Escritura y teología dogmática: "Si se examinan los fundamentos bíblicos de la cristología escolástica, la siguiente observación no es falsa o injusta: le bastan unos pocos textos bíblicos. Desde el principio su meta es el dogma efesino-calcedónico y solo eso. De las afirmaciones de la Escritura sobre Cristo, en sus propios labios o en la enseñanza de los apóstoles, interesan solo los textos que es posible traducir, de la manera más directa, a esa cristología metafísica clásica. El método es legítimo. Pero incompleto", concluye Rahner ${ }^{46}$. Y podría añadirse, esbozada en otro lugar del mismo artículo, una tercera insuficiencia metodológica, a partir de la constatación de la casi inexistencia de controversias vivas en la cristología católica que apasionen e interesen existencialmente a los cristianos. Esa carencia tiene que ver con la desatención a las "peculiaridades de nuestra situación espiritual", al "punto de vista histórico único" dado, que condiciona la perspectiva de acceso a las verdades teológicas y que permite asumirlas vitalmente. "El hombre entiende lo que escucha de manera más exacta teoréticamente y más viva existencialmente en la medida en que a lo escuchado lo comprende en relación con el contenido total de su existencia espiritual" ${ }^{77}$.

Esto explica la primera parte del artículo orientada a mostrar, precisamente, lo que se insinúa en el título original del mismo: "Calcedonia (es decir aquí, esta fórmula dogmática): ¿fin o comienzo?» (cursiva mía). Los argumentos aquí explicitados, sobre la evolución de una definición dogmática, pueden sintetizarse en la expresión rahneriana: la autotrascendencia de toda fórmula; que es el resultado de tomar en serio la historici-

Karl Rahner como hermenéutica teológica del mundo y de la praxis», Teología y Vida 45 (2004) 411-437.

45 Cf. «Probleme der Christologie von heute», 276.

46 «Probleme der Christologie von heute», 276.

47 «Probleme der Christologie von heute», 264. 
dad de la verdad. «Toda verdad del Dios que se revela, porque está dada como camino e impulso hacia la comunión inmediata con él, es apertura hacia lo inabarcable, comienzo de lo ilimitado ${ }^{48}$. La formulación más clara, más precisa, más sagrada es «comienzo no fin, medio y no meta, una verdad que libera para la verdad, siempre mayor» ${ }^{49}$. Están aquí condensadas ideas y presupuestos muy caros a la teología rahneriana.

Con estos elementos, Rahner afronta en la primera sección del artículo una precisa tarea: mediante "una hermenéutica trascendental a partir del dogma», mostrar que el dogma cristológico no tiene la pretensión de ser la "condensación adecuada de la enseñanza bíblica» y que, por tanto, «a partir de él» (von ihm her) hay espacio para una «ulterior teología bíblica cristológica " ${ }^{50}$. El autor especifica que solo en este sentido habla en lo que sigue de teología bíblica. Al final de la sección afirma nuevamente: «interrumpimos aquí el ejercicio de teología bíblica, o dicho más exactamente, la hermenéutica trascendental para una teología bíblica cristológica» ${ }^{51}$ ¿QQué quiere expresar el autor con "hermenéutica trascendental»? Una cuestión es puesta en el plano trascendental cuando se interroga sobre las condiciones a priori del conocimiento, en un sujeto cognoscente, que hacen posible el conocimiento de un objeto concreto $^{52}$. Una hermenéutica trascendental puede entenderse aquí, entonces, como una interpretación que trata las condiciones a priori que hacen posible el conocimiento del dogma cristológico y que interroga al dogma para determinar qué acceso le ofrece a la teología bíblica ${ }^{53}$. En concreto, la tarea que Rahner realiza es repensar las categorías de la cristología clásica a partir de los resultados de la teología bíblica, caracterizada aquí, particularmente, en dos términos: mesías y mediador. ¿Qué implican ambas afirmaciones bíblicas para la teología clásica? La afirmación de la verdadera autonomía, la originalidad del hombre Jesús en su relación a Dios. Tanto la mesianidad como la mediación suponen la afirmación de su humanidad, contra lo que llama una mitologización: lo humano sería un revestimiento, un instrumento del cual el Verbo se

\footnotetext{
48 «Probleme der Christologie von heute», 261.

49 «Probleme der Christologie von heute», 261.

50 «Probleme der Christologie von heute», 265.

51 «Probleme der Christologie von heute», 280 (cursiva mía).

52 Cf. K. Rahner, «Überlegungen zur Methode der Theologie», 98.

53 Cf. E. Maurice, La christologie de Karl Rahner, 75.
} 
sirve, sin que lo humano adquiera su «más alta originalidad y autodisposición, porque ha sido asumida por Dios $»^{54}$. Tomar en serio la humanidad de Jesús en su rol de mediador es el desafío que Rahner propone a la teología clásica y para ello recurre a la teología bíblica: «...la Biblia puede decirnos todavía algo más a propósito de esta teología clásica de la encarnación ${ }^{55}$.

Dejo una observación metodológica para el punto siguiente, pero introduzco aquí una breve digresión para recoger, de la mano de Maurice, una evaluación de la relación Cristología - Escritura en el conjunto de la obra de Rahner. En cierto sentido, se ha verificado en este texto de 1954 una confrontación entre la teología bíblica y la teología clásica, que es punto de partida de una renovación teológica. Pero si se tiene en cuenta su tesis doctoral de 1936 en adelante, se observa con los años «un eclipse en la utilización de la Escritura que no puede pasar inadvertido» ${ }^{56}$. Es verdad que el análisis del Curso fundamental sobre la fe (1976), texto de madurez en particular referido a la cristología, merece una consideración especial atendiendo a su objetivo principal: afrontar lo que Rahner llama el "primer nivel de reflexión». Pero en el conjunto del emprendimiento cristológico, constata Maurice hacia el término de su trabajo en un tono deliberadamente moderado, la Escritura está «implícitamente presente en el corazón de las reflexiones rahnerianas», solo implícitamente. "De hecho mientras más progresa la argumentación conceptual, menos interviene la Escritura en el razonamiento" ${ }^{57}$. Excede las posibilidades de este artículo explicitar estas frases de manera más detallada.

\section{5. «Sobre la inspiración de la Escritura» (1956) - Una Clave METODOLÓGICA}

Particularmente conocida ha sido la contribución de Rahner a la comprensión de la inspiración de la Escritura, sobre todo por la difusión que obtuvo su trabajo Über die Schriftinspiration, que, en 1958, inauguraba la colección Quaestiones disputae editada por él mismo y por H. Schlier.

\footnotetext{
54 «Probleme der Christologie von heute», 267 nota 6.

55 «Probleme der Christologie von heute», 267.

56 Cf. E. Maurice, La christologie de Karl Rahner, 242.

57 Cf. E. Maurice, La christologie de Karl Rahner, 243. Cf. no obstante algunas iniciativas en torno a la cristología sistemática en relación con la exégesis a que aludo más abajo.
} 
La dedicación a esta temática parece estar concentrada en una determinada época en la vida de Rahner, entre 1956 y 1963, aunque pueden encontrarse breves desarrollos sobre el tema en textos posteriores, sin que se añada ya nada esencial ${ }^{58}$. La versión original, más breve, se remonta a dos años antes: una conferencia en la Universidad de Würzburg en enero de 1956, publicada ese mismo año ${ }^{59}$. De allí que su interés no tiene que ver inmediatamente con su posterior participación en algunas discusiones en el proceso de formación de la futura Constitución Dei verbum del Vaticano II. Pero, como puede advertirse, tanto la metodología empleada para abordar el tema como las ideas centrales pertenecen al corazón del emprendimiento rahneriano. Debe reconocerse, no obstante, que no está claro cómo Rahner llegó a este tema; probablemente se reúnen aquí ideas ya trabajadas que explicitan la manera cómo debe afrontarse la Escritura ${ }^{60}$, también es posible, típico en Rahner, que la dedicación al tema se deba a la solicitud de una conferencia. Presto atención aquí, no tanto a la precisión de la explicación de la causalidad divina de la Escritura, a su autoría divina, sino al contenido de la misma en cuanto implica una reflexión sobre la Escritura, en sí misma y en su relación con la Iglesia (y la teología), que, por otra parte, es el núcleo del tema que a Rahner ocupa aquí. Probablemente es esta perspectiva, también, una de sus contribuciones al progreso teológico de este asunto en aquel momento, previo al Concilio ${ }^{61}$.

El trabajo de 1956/1958 no es de teología bíblica, sino dogmático, aborda, como punto de partida, la doctrina de la inspiración, «tal como ha sido fijada en sus líneas fundamentales por el magisterio y en la escuela es desarrollada y expuesta ${ }^{62}$. Rahner la resume escuetamente de la

58 Cf., por ej., Grundkurs des Glaubens. Einfiihrung in den Begriff des Christentums (Freiburg i.Br. 1976) 358-365; "Die Heilige Schrift - Buch Gottes und Buch der Menschen", Stimmen der Zeit 202 (1984), 35-44; reproducido en Schriften zur Theologie. Bd. 16 .

59 «Über die Schriftinspiration», Zeitschrift für katholische Theologie 78 (1956) 137-168.

60 Cf. K. H. Neufeld, «Die Schrift in der Theologie Karl Rahners», 232.

${ }^{61}$ Cf. H. Hoping, «Theologischer Kommentar zur Dogmatischen Konstitution über die göttliche Offenbarung "Dei Verbum”" en P. Hünermann - B. J. Hilberath (eds.), Herders Theologischer Kommentar zum Zweiten Vatikanischen Konzil. Band 3 (Freiburg i.Br. 2005) 695-831, 707s., 766ss.

62 Über die Schriftinspiration (Freiburg i.Br. 1958) 16. 
siguiente forma: «la Escritura tiene a Dios como autor; es autor en un sentido literario..., lo es porque ha inspirado la Sagrada Escritura. Esa inspiración de la Escritura no consiste en que ella es reconocida como canónica por la Iglesia, tampoco simplemente porque transmite la revelación de Dios sin error. La inspiración consiste, más bien, en que Dios ilumina sobrenaturalmente al autor humano en la captación del contenido y de los planes esenciales de su Escritura; lo mueve voluntariamente a escribir todo y solo lo que Dios mismo quiere escribir y, tercero, lo asiste para que la obra captada intelectualmente y voluntariamente querida pueda realizarse conforme a ello». Concluye esa descripción de la siguiente forma: «ese concepto, su validez y sus fuentes dogmáticas pueden ser aquí supuestas y consideradas válidas» ${ }^{63}$. El resultado de su trabajo en este punto, piensa Rahner, es la adquisición de un concepto de inspiración que «recoge, confirma y aclara» la noción tradicional ${ }^{64}$.

A partir de esta definición tradicional, la tarea a ojos de Rahner (con una metodología que enseguida explicito) consiste en superar «un cierto carácter abstracto" del concepto, "que podría ser completado mediante un contenido material $\aleph^{65}$. O, en otros términos, se pretende formular una "determinación más precisa» del concepto de inspiración ${ }^{66}$, más exactamente, debe ser comprendido a partir de la convicción fundamental de la fe cristiana, al interior del conjunto sistemático de la teología, no meramente a partir de una consideración sobre la temática de la causalidad instrumental. El "punto de partida» se formula así: "La Iglesia primitiva como fundamento permanente y norma de la fe de la Iglesia para todos los tiempos ${ }^{67}$. La cadena de razonamientos sigue el siguiente orden: (a) En Jesucristo y su Espíritu, tal como ha sido testimoniado en los tiempos apostólicos, está dada la absoluta e irreversible autorrevelación de Dios. No hay que esperar una nueva revelación posterior, sino su cumplimiento y plenitud. (b) La Iglesia es la comunidad visible,

63 Über die Schriftinspiration, 19-20.

64 «Inspiration», Handbuch Theologischer Grundbegriffe. Bd. 1 (München 1962), 715725, 722 (Sämtliche Werke. Bd. 12, 240-250, 247). Idéntico en «Über die Inspiration der Schrift», en L. KLeIN (ed.), Diskussion über die Bibel (Mainz 1963) 7-16 (Sämtliche Werke. Bd. 12, 209-215, 213).

65 Über die Schriftinspiration, 18. Cf. Über die Schriftinspiration, 26, 37, 86.

66 Über die Schriftinspiration, 46.

67 «Inspiration», 721 (SW 12, 246). 
histórico-escatológica fruto de dicha autocomunicación. (c) La Iglesia primitiva (en sentido histórico-teológico necesitado de una determinación ulterior), por su parte, es querida por Dios como el fundamento permanente y la norma infalible de todo tiempo futuro de la vida de la Iglesia. Ella no es simplemente la primera fase temporal, sino la medida de la Iglesia posterior. (d) Aunque de lo dicho no puede deducirse necesariamente la existencia de la Escritura, el efectivo ejercicio de esa norma non normata «apenas puede ser pensado de otra manera más que mediante un depósito escrito de esa Iglesia primitiva ${ }^{68}$. La Escritura, en este sentido, es la realización vital y esencial de la Iglesia primitiva. Precisamente, «la convicción de que la Escritura pertenece a los elementos constitutivos de la Iglesia primitiva como fuente y norma de la fe de los tiempos posteriores es una convicción de fe apostólica ${ }^{69}$. En ese marco teológico se inserta la «idea fundamental» de Rahner sobre la inspiración: es «un momento interno a la fundación divina de la Iglesia ${ }^{70}$, «un momento interno de la formación de la Iglesia primitiva» ${ }^{71}$. En este sentido debe comprenderse su afirmación: la razón que explica por qué Dios es el autor de la Escritura es porque ella es el libro de la Iglesia primitiva $^{72}$.

Desde esta perspectiva se hace más comprensible, también, la intrínseca relación entre la Iglesia (con su magisterio) y la Escritura. Esta ha sido querida por Dios «como la misma palabra objetivada de la Iglesia»" ${ }^{73}$. No ha sido confeccionada por Dios y entregada a la Iglesia de una manera extrínseca. La Biblia surge como un proceso vital de la misma Iglesia. $\mathrm{Y}$ «porque es $s u$ palabra» ${ }^{7}$, puede interpretarla autoritativamente. «Magisterio infalible de la primitiva iglesia es la capacidad de formación de la Escritura. Magisterio infalible de la Iglesia según la iglesia primitiva es la explicación autoritativa de la Escritura» ${ }^{75}$. No estamos frente a dos

\footnotetext{
68 «Inspiration», 722 (SW 12, 247).

69 «Inspiration», 722 (SW 12, 247). Cf., también, Über die Schriftinspiration, 74, 76.

70 Über die Schriftinspiration, 65.

71 Über die Schriftinspiration, 47.

72 Cf. Über die Schriftinspiration, 78.

73 «Über die Inspiration der Schrift», 15 (Sämtliche Werke. Bd. 12, 214) (cursiva en original).

74 «Inspiration», 723 (SW 12, 248) (cursiva en original).

75 Über die Schriftinspiration, 80 (cursiva en original).
} 
«Entiendes de exégesis menos de lo deseable». La Escritura en la obra de Karl Rahner | 127

infalibilidades unidas arbitrariamente, están constituidas intrínsecamente dependientes una de otra; "son dos momentos recíprocamente relacionados del mismo suceso esencial ${ }^{76}$. Para entender uno, hay que comprender al otro. La canonicidad, por su parte, representa «el conocimiento reflejo de la pertenencia de esa Escritura a la autoconstitución de la Iglesia» ${ }^{77}$, lo cual requiere más tiempo que la realización de la inspiración.

Una breve evaluación. La cuestión de la inspiración no parece ser un tema de relieve en la discusión teológica actual, como lo fue, incluso en el momento previo al Concilio, constata en un importante simposio el biblista alemán, H. Gabel. A su juicio, los intentos de comprensión del tema de las últimas tres décadas pueden clasificarse, de manera un poco simple, en tres modos de acceso: como constitución de la comunidad de fe, como un suceso de lectura y recepción, como la inspiración, pneumatológica, del hombre creyente. Es en el primer campo donde se sitúa el aporte de Rahner: «en buena medida determina hasta hoy» la reflexión sobre el tema y «su valoración y recepción» no cesa ${ }^{78}$. Permite comprender el proceso de surgimiento de la Biblia en su complejidad y procesualidad, en su completa humanidad. En particular, la vinculación entre Biblia e Iglesia y la estrecha relación de la Escritura con la Tradición son los puntos más destacados. Paralelamente, ha sido advertida la necesidad de ulteriores precisiones o complementos, sobre todo en cuatro áreas: una diferenciación de la noción de Urkiche, una mayor precisión de la normatividad de dicha Iglesia primitiva para todos los tiempos en beneficio de la normatividad del kerygma apostólico, una reflexión cristológica y pneumatológica más explicita y, cuarto, el déficit en la explicación de la inspiración aplicada a los textos veterotestamentarios, quizás el punto más discutido, como afirma C. Dohmen ${ }^{79}$. Según

76 Über die Schriftinspiration, 80.

77 Über die Schriftinspiration, 76.

78 H. Gabel, «Inspiration und Wahrheit der Schrift (DV 11). Neue Ansätze und Probleme im Kontext der gegenwärtigen Wissenschaftlichen Diskussion», en L'Interpretazione della Bibbia nella Chiesa. Atti del Simposio promosso dalla Congregazione per la Dottrina della Fede (Città del Vaticano 2001), 64-84, 66s. Cf., también, del mismo autor, Inspirationsverständnis im Wandel. Theologische Neuorientierung im Umfeld des Zweiten Vatikanischen Konzils (Mainz 1991), 128-150.

79 «Muss der Exeget Theologe sein? - Vom rechten Umgang mit der Heiligen Schrift», Trierer Theologische Zeitschrift 99 (1990), 1-14, 7-8. El autor destaca que la pro- 
muestran estos autores con varios testimonios, las ideas de Rahner en este punto han sido asumidas y ulteriormente desarrolladas por buena parte de los biblistas contemporáneos a él; ambos destacan particularmente el trabajo de P. Grelot, también los de K.-H. Ohlig, M. Limbeck y Alonso-Schökel.

Antes de cerrar este punto, formulo dos observaciones referidas al aspecto metodológico. (1) Se observa con claridad en el desarrollo aquí sintetizado una búsqueda central en Rahner: razonabilidad, y así credibilidad de los enunciados teológicos. Esta tarea se realiza buscando una razón intrínseca que la explique, no una mera decisión arbitraria de Dios, situando la afirmación de fe analizada en el marco del conjunto de la fe cristiana, por una parte, y, por otra, en relación al núcleo de la fe ${ }^{80}$. Y todo ese proceso con una "vuelta a la experiencia», atención al oyente del mensaje. De allí que Rahner piense que su presentación de la inspiración "recoge, confirma y aclara» la noción tradicional. (2) Es claro que estamos aquí con "un modo de trabajo teológico», usando las palabras anteriormente citadas de K. Neufeld pero aplicadas aquí en otro sentido, típico de Rahner que representa, quizás, el hilo conductor metodológico principal en la obra del teólogo alemán. En una importante entrevista de 1974 ya citada, Rahner describe su propio itinerario como teólogo. Sobre la orientación fundamental de su trabajo afirma:

Es una reflexión especulativa sobre datos disponibles en la conciencia general de la fe y en la teología de escuela. (...) Intenté desentrañar el poder y el dinamismo internos que están ocultos en la teología escolástica. Pero tampoco eso ha sucedido intencionadamente en una reflexión formal sobre un método determinado, sino solo de hecho. La teología de escuela ofrece en sí misma tantos problemas y tanta dinámica para poder desarrollarse al interior de ella misma y también,

puesta de Rahner ha sido valorada como «el más importante impulso» para una comprensión teológica de la inspiración. Cf., también la, posición más crítica de A. Artola, que incluye un interesante informe sobre la recepción internacional del texto de Rahner, en La Escritura inspirada. Estudios sobre la inspiración biblica (Bilbao 1994), 159-181. Al final, el autor afirma: «la monografía de Rahner ha significado el último importante intento de una nueva sistemática en materia de inspiración».

80 «Heilige Schrift und Tradition» en Schriften zur Theologie. Bd. 6: Neuere Schriften (Einsiedeln 1965), 121-138, 136-137. 
superarse a sí misma en un cierto salto cualitativo que, como un simple teólogo de escuela, se pueden hacer considerables progresos ${ }^{81}$.

Es interesante advertir, también, que dicha perspectiva metodológica, central para la comprensión de la obra de Rahner, es quizás la principal causa de su innegable repercusión internacional, no obstante las dificultades para su comprensión, también debidas al idioma alemán. Es la acertada observación de Karl Lehmann: «Probablemente es la "teología de escuela”, punto de partida de muchas reflexiones rahnerianas, un fundamento que explica por qué sus razonamientos pudieron alcanzar una fuerza expansiva internacional, grande y asombrosa. Todo teólogo podía seguir el desarrollo posterior» ${ }^{82}$. Esta perspectiva puede explicar por qué Rahner jugará luego un rol importante, ni único ni principal, en el «primer conflicto doctrinal» del Concilio (G. Ruggieri), el rechazo del Esquema preparatorio De fontibus revelationis, con la famosa votación de noviembre de 1962 que algunos autores han leído en términos epocales: constituiría el fin del dominio del método neoescolástico en la teología de la Iglesia católica ${ }^{83}$.

6. «EXÉGESIS Y DOGMÁTICA» (I96I) - «¿ES USTED PIANISTA O MÚSICO?» UN «EXPERIMENTO»

Un texto peculiar es el fruto de una conferencia en Paderborn en enero de 1961, publicada ese mismo año en diferentes revistas e incorporada a los Schriften zur Theologie en $1962^{84}$. Al inicio Rahner explicita una motivación más general y otra más concreta que dan origen al texto: «ha surgido de la impresión que dentro de la teología católica impera un cierto extrañamiento entre los representantes de esas dos disciplinas», una cierta desconfianza, incluso irritación ${ }^{85}$. Los exégetas se preocuparían poco de la teología a la que el teólogo dogmático se siente vinculado,

81 «Gnade als Mitte menschlicher Existenz», 80.

82 «Karl Rahner. Ein Porträt» en K. Lehmann - A. Raffelt (eds.), Rechenschaft des Glaubens, Karl Rahner-Lesebuch (Freiburg i.Br. 1979), 13*-53*, 19*.

83 Cf. J. F. X. Pratt, The Day Neo-Scholasticism Died: November, 201962 (Nashville 2002), 2. Consultado en http://proquest.umi.com/pqdweb?RQT $=302 \& c f c=1$ (julio de 2010). Cf. allí otras opiniones concordantes.

84 «Exegese und Dogmatik», Orientierung 25 (1961), 141-144, 157-162; Stimmen der Zeit 168 (1961), 241-262; (Schriften zur Theologie. Bd. 5, 82-111; Sämtliche Werke. Bd. 12, 171-192; cito según esta última impresión).

85 «Exegese und Dogmatik», 171. 
los dogmáticos, por su parte, querrían imponer ataduras que no estarían objetivamente justificadas, ya que ellos no habrían advertido suficientemente los progresos que ha hecho la exégesis. Rahner refiere, también, muy críticamente a un artículo relevante de A. Romeo publicado en 1960 contra los profesores del Pontificio Instituto Bíblico, contra la "exégesis católica alemana», las «brumas nórdicas»" ${ }^{86}$ H. Vorgrimler añade también otro suceso: la difusión que había obtenido la crítica del reconocido exégeta suizo, $\mathrm{H}$. Haag, a la doctrina del pecado original ${ }^{87}$, tema sobre el cual Rahner se había expresado en diversas oportunidades. Rahner constata allí que la dificultad, entonces, está más vinculada al Nuevo Testamento que al Antiguo.

El artículo está dividido en tres partes: primero, dirige, como dogmático, la palabra a los exégetas, en segundo lugar, habla (efectivamente, tiene un estilo y tono coloquial), como colega, a los dogmáticos y, finalmente, añade unas «reflexiones ulteriores». Particularmente las dos primeras son de utilidad inmediata para esta contribución. Es claro que, ya a partir del estilo mismo del artículo, no puede esperarse que se encuentre allí un tratamiento omnicomprensivo del asunto. La atención se concentra en un par de ideas centrales y busca afrontar un momento concreto de tensión entre ambas disciplinas teológicas: la exégesis y la dogmática. La tercera parte del artículo, más breve, no la afronto aquí: refiere a la común responsabilidad, de exégetas y dogmáticos, frente a los

86 La conocida "controversia romana» se remonta a los años 50 y alcanzó su punto culminante en la fase preparatoria del Concilio. Fue una disputa entre exégetas, teólogos e instituciones (Universidad Lateranense y el Pontificio Instituto Bíblico). Autores del Bíblico (Lyonnet, Schökel, etc.) apoyaban la utilización del método histórico-crítico; los de la Universidad Lateranense (Spadafora, Romeo, etc.) veían en ella una metodología modernista e innecesaria dada la infalibilidad de la Biblia. La ríspida controversia, que implicó a los rectores, al Santo Oficio e, incluso, a Juan XXIII, revela el nivel de la problemática al iniciarse el Concilio. El esquema preparatorio De fontibus, representaba bien la posición del Laterano. Cf. el interesante panorama de la controversia y, en particular, los asuntos y argumentos utilizados entonces en A. Dupont - K. Schelkens, "Katholische Exegese vor dem Zweiten Vatkanischen Konzil (1960-1961)", Zeitschrift für katholische Theologie 132 (2010) 1-24.

87 Cf. H. Vorgrimler, «Editionsbericht» en Sämtliche Werke. Bd. 12, XI-XXII, XV. De hecho Rahner alude brevemente a la temática, aunque sin citar a Haag. Cf. «Exegese und Dogmatik», 184. 
«Entiendes de exégesis menos de lo deseable». La Escritura en la obra de Karl Rahner | 131

intelectuales cristianos de hoy y, más en general, en relación a la fe de la Iglesia y su transmisión.

El núcleo de la primera parte, dirigida a los exégetas, aflora inmediatamente: que «la exégesis es propiamente una ciencia teológica resume todo lo que sigue» ${ }^{88}$. El trabajo exegético debe ser concebido como «un momento interno de la teología católica como tal»; constituye una "ciencia de la fe», no solo filología o ciencia de la religión ${ }^{89}$. Por el contrario, la situación que Rahner percibe la expresa con claridad en un tono coloquial y crítico:

Tengo la impresión que ustedes hacen su trabajo, con frecuencia alegre y animosamente, en el estilo del mero filólogo y del historiador profano, y cuando aparecen dificultades, problemas para la teología dogmática o para la conciencia de la fe de sus jóvenes teólogos o de los laicos, ustedes aclaran: Esto no es cosa «nuestra», es cosa del dogmático, que ellos vean cómo pueden arreglarse. (...) Se tiene a veces la impresión de que ustedes experimentan algo así como la cima y prueba de la autenticidad y del carácter científico de su ciencia, cuando pueden descubrir dificultades. (...) ¿No se escudan ustedes demasiado rápido en algunos lugares tras la aclaración de que al exégeta le incumbe solamente constatar el sentido inmediato de la palabra de la Escritura, y todo lo que vaya más allá de esto no sería ya su oficio? ${ }^{90}$.

De lo dicho, la exégesis católica es una ciencia de la fe, se deduce que la fe de la Iglesia y sus enseñanzas no deban ser pensadas solo como una «norma negativa», un límite que no puede superarse, sino más bien como "un principio de investigación positivo interior del mismo trabajo exegético» ${ }^{91}$. Lo dicho, no opaca otra afirmación dirigida a los exégetas: «ustedes deben ser críticos, despiadadamente críticos», no buscando «una conciliación deshonesta entre los resultados de la ciencia y la doctrina eclesiástica»; pero la mostración de la armonía entre los resultados de la exégesis y la enseñanza de la Iglesia es una «tarea originalmente propia» de los exégetas, no solo de los teólogos dogmáticos. «Pues ustedes son teólogos católicos», advierte Rahner ${ }^{92}$. De allí que una de sus

\footnotetext{
88 «Exegese und Dogmatik», 174.

89 «Exegese und Dogmatik», 173 (cursiva mía).

90 «Exegese und Dogmatik», 174-176.

91 «Exegese und Dogmatik», 174.

92 «Exegese und Dogmatik», 174 (cursiva mía).
} 
principales tareas sea la atención a los puentes entre exégesis y dogmática que, precisamente los exégetas por su formación y conocimiento, están capacitados para afrontar, naturalmente, junto con los dogmáticos ${ }^{93}$. Rahner esboza brevemente en este contexto la intrínseca relación entre magisterio, tradición y Biblia; pone el acento, explicablemente, en la problemática que representa una verdad implícita en la Biblia. El magisterio, por su parte, debe situarse en su justo lugar, no es «fuente material de una verdad revelada", es "portador de una verdad de fe, portador de una posible explicación» ${ }^{94}$, un momento interno del trabajo teológico.

Tres recomendaciones ulteriores a los exégetas pueden advertirse en el texto. Un mejor conocimiento de la teología de escuela por parte de ellos ayudaría a la relación entre ambas disciplinas, incluso facilitaría el mismo trabajo exegético ${ }^{95}$. En segundo término, una mayor conciencia de "cuáles principios a priori de naturaleza dogmática y teológico-fundamental» están operando y deberían operar en el trabajo bíblico debería ser reflexionado más explícitamente ${ }^{96}$. Finalmente, Rahner reconoce que es un reproche injusto que se hace a los exégetas católicos el adoptar enseñanzas provenientes de la exégesis evangélica. Pero, también aquí, Rahner formula una advertencia, más comprensible en aquel momento: "¿No deberían evitar la impresión de que una tesis evangélica es para ustedes más probable porque ha crecido originalmente en el suelo de la exégesis evangélica y no en el de la católica? ¿Y no deberían también pensar que la teología evangélica se acerca frecuentemente a la Escritura con un a priori filosófico, no con un método objetivamente justificado, crecido de la exégesis misma?» ${ }^{97}$.

En la segunda parte del artículo, dirigida a los teólogos dogmáticos, sus colegas, Rahner no aparece menos exigente. La primera responsabi-

93 En un texto posterior, de 1963, Rahner habla de la teología bíblica como «momento interno de la dogmática», no simplemente yuxtapuesto como otros momentos de teología histórica, sino como "momento privilegiado y único» que, en una reforma de estudios, preveía entonces el autor, podría ser «un ramo propio», "una ciencia propia», no mera "prolongación de la exégesis», ni mero "momento interno de la dogmática», que "presente la mediación correcta entre dogmática y exégesis», K. RAHNER, «Heilige Schrift und Theologie» en Schriften zur Theologie. Bd. 6, 111-120, 120.

94 «Exegese und Dogmatik», 175.

95 Cf. «Exegese und Dogmatik», 176.

96 «Exegese und Dogmatik», 178. Cf. «Exegese und Dogmatik», 186.

97 «Exegese und Dogmatik», 179. 
lidad del dogmático es la de concretar un trabajo bíblico, convincente para los mismos exégetas. "Si quieres hablar entre los exégetas, debes entender realmente el manejo de su instrumento de oficio, debes haber rastreado de veras el peso de sus reflexiones, de sus problemas» ${ }^{98}$. Dada la complejidad y lo inabarcable de la ciencia actual, Rahner se pregunta qué teólogo dogmático puede acceder no solo a los resultados, sino al proceso mismo de elaboración de los estudios. «Es hoy infinitamente difícil entender tanto de otra ciencia, que se pueda entrar en conversación en ella ${ }^{99}$. En ese marco, Rahner realiza una expresa justificación de la importancia y las dificultades del trabajo histórico de los exégetas, que reclaman una comprensión del teólogo dogmático. En particular, piensa Rahner, el dogmático puede ayudar al exégeta si, manteniendo una afirmación que se considera teológicamente correcta o vinculante del magisterio, ella es explicada de una manera que muestre, más claramente de lo que se logra ordinariamente, que la preocupación de sus colegas exégetas no le es ajena, "que entiendes de alguna manera el manejo de sus métodos y que sabes valorar sus resultados ${ }^{100}$. Un planteo claro y sensible a la perspectiva de los otros facilitaría el trabajo bíblico, tendría para el exégeta efectos liberadores. Se trata de un esfuerzo de aproximación "para hacer comprensible al teólogo bíblico, que teología bíblica y teología dogmática de escuela afirman de hecho una misma realidad ${ }^{101}$.

Es claro que el núcleo del artículo se orienta a subrayar ante todo el carácter de teología católica que posee la exégesis bíblica. No hay duda también que Rahner toca aquí un problema fundamental, simpáticamente expresado en la observación de H. Schürmann: "A la pregunta, “¿es usted exégeta o teólogo?”, debería repreguntarse “¡es usted pianista o músico?” " ${ }^{102}$. Está fuera del campo de esta contribución prestar atención a la recepción que este texto tuvo en la comunidad teológica. La discusión con el exégeta N. Lohfink algunos años después, en 1968,

\footnotetext{
98 «Exegese und Dogmatik», 179.

99 «Exegese und Dogmatik», 180.

100 «Exegese und Dogmatik», 181.

101 «Exegese und Dogmatik», 182. Rahner acude en ese contexto a diversos ejemplos: la conciencia de Jesús, el pecado original, etc.

102 Citado en R. Kampling, «Exegese und Karl Rahner», en M. Delgado - M. LutzBachmann (eds.), Theologie aus Erfahrung der Gnade. Annährungen an Karl Rahner (Berlin 1994), 267-283, 274.
} 
afronta una problemática distinta en otro contexto: el de la reforma de los planes de estudio luego del Vaticano $\mathrm{II}^{103}$. Dicha discusión se centra en buena medida en el espacio que Rahner ha previsto para los estudios bíblicos en su propuesta de reforma; no tiene un interés inmediato para nuestro trabajo, salvo en la medida en que pone una pregunta de relieve a un proyecto importante de Rahner, aquí denominado "Curso fundamental: teología de la decisión» ${ }^{104}$, que se materializaría en el libro Grundkurs des Glaubens, publicado en 1976, pero elaborado en sus años de docencia en Munich (1964-1967) y Münster (1967-1971) ${ }^{105}$.

Una iniciativa académica de K. Rahner en línea con el artículo de 1961, en el semestre de invierno 1970/71 en Münster, que califica de experimento, ha sido valorada positivamente. Se trata de un curso de sistemática que dieron en forma conjunta con el biblista W. Thüsing. La iniciativa se plasmó en un libro: Christologie - systematisch und exege$t_{i s c h}{ }^{106}$. Más importante que el texto lo constituyeron las mismas clases, a las cuales asistían ambos profesores. El texto, previamente escrita la parte de Rahner y entregada a los alumnos al inicio de las clases, no refleja completamente ese valioso trabajo conjunto en el aula. El prólogo, firmado por ambos, expresa el desafío del trabajo interdisciplinar: mientras se hace esperar una reforma de los estudios teológicos, escriben, «se requieren ciertos experimentos». «En la actual situación universitaria, esto solo se logrará si los profesores que imparten las diversas disciplinas dialogan entre sí y los estudiantes pueden seguir estos debates parti-

103 K. Rahner, "Zur Neuordnung der theologischen Studien», Stimmen der Zeit 181 (1968), 1-21; N. Lohfink, "Text und Thema. Anmerkungen zum Absolutheitsanspruch der Systematik bei der Reform der theologischen Studien», Stimmen der Zeit 181 (1968) 120-126; K. Rahner, «Die Exegese im Theologiestudium: Eine Antwort an N. Lohfink», Stimmen der Zeit 181 (1968), 196-201; K. Rahner, Zur Reform des Theologiestudiums (Quaestiones disputatae 41, Freiburg i.Br. 1969). Los textos de Rahner están recogidos ahora en Sämtliche Werke. Bd. 16, 434-455, 456-462, 463-530.

104 K. Rahner, «Die Exegese im Theologiestudium», 198 (Sämtliche Werke. Bd. 16, 458).

105 Cf. C. Schickendantz, «El "Curso fundamental de la fe" de Karl Rahner. Objetivo, génesis y significado de un "experimento"”, Teología y Vida 45 (2004) 137-156.

106 W. ThüsIng - K. Rahner, Christologie - systematisch und exegetisch (Freiburg i.Br. 1972) (la parte de Rahner: "Grundlinien einer systematischen Christologie», 1778). Citamos aquí la edición castellana: Cristología. Estudio teológico y exégetico (Madrid 1975). Las citas aquí, del prólogo, cf. ibid., 15-18. 
cipando en ellos». Dicha enseñanza de tipo interdisciplinar, constatan Rahner y Thüsing, que debe centrarse en los alumnos y superar la visión de un conglomerado de datos fragmentarios en diversas disciplinas, está «entre las aspiraciones más importantes de la reforma de los estudios». En ese contexto los autores recuerdan las obligaciones recíprocas de exégetas y sistemáticos para aproximarse y facilitar un trabajo común ${ }^{107}$.

\section{7. ÁMBITOS O PERSPECTIVAS ULTERIORES DE TRABAJO}

Interrumpo aquí el ya largo camino, por lo demás, manifiestamente incompleto. ¿Qué nuevos aspectos del trabajo rahneriano podrían o deberían tematizarse para una adecuada comprensión del asunto que nos ocupa? Una línea a trabajar, por ejemplo, sería verificar la utilización que el autor ha hecho de algunos pasajes bíblicos concretos. El texto bíblico más citado en toda la obra es $M t$ 25,31-46, aunque nunca concreta un análisis exegético del mismo, sino que lo supone. Esa cita aparece, sobre todo, en dos contextos importantes. El primero, al afrontar la temática de la unidad del amor a Dios y al prójimo: el encuentro con el otro «es el acto fundamental y abarcativo en la existencia del hombre». Y en esa apertura al prójimo, el mismo Dios es alcanzado, de modo que aquel no es nunca solo una ocasión. Que encontramos a Dios en el «sacramento del hermano", Rahner lo fundamenta con dos citas bíblicas, la de Jn 1,4$20 \mathrm{y}$, sobre todo, la de $\mathrm{Mt}$ citada $^{108}$. Interesante para revisar ulteriormente es la relación que pueda existir entre su famosa tesis del cristianismo anónimo y dicha cita neotestamentaria.

Otro texto bíblico que jugó un rol significativo, particularmente en la década del 50, fue el de $M t 27,52 s$. que, con ocasión de la definición de la Asunción de María, refería a otro tema caro a Rahner: la unidad del hombre y el significado esencial de la resurrección para el futuro humano, personal y comunitario. Buscando inteligibilidad a la situa-

107 Cf. también otro intento de Rahner, cristológico «entre la exégesis y la dogmática», de mostrar las «convergencias internas» que hay entre los estudios histórico-críticos que muestran la historicidad en la autoconciencia de Jesús, prepascual y la «cristología eclesial»y, en segundo término, sobre la problemática de la resurrección, «Kirchliche Christologie zwischen Exegese und Dogmatik», en Schriften zur Theologie. Bd. 9, 197-226.

108 Cf. una reflexión más amplia al respecto y la lista de los lugares donde aparece la cita de Mateo en Rahner, N. Schwerdtfeger, Gnade und Welt. Zum Grundgefüge von Karl Rahners Theorie der "anonymen Christen" (Freiburg i.Br. 1982), 287-289. 
ción definitiva de María definida en el nuevo dogma, afirmaba que las dificultades que pudieran ponerse contra esa posibilidad, en el sentido de una resurrección individual «ya realizada» anterior a la salvación del conjunto de la humanidad y a la transfiguración de toda la realidad cósmica, tropiezan contra el dogma fundamental de la resurrección del Señor. En Jesucristo, un hombre posee ya la consumación total mediante la resurrección ${ }^{109}$. En él el fin como plenitud ya está inaugurado y presente. Lo que se denominan «realidades últimas» ya han acontecido en Cristo. Por eso, afirma Rahner, «nosotros esperamos como nuestro futuro el "pasado" (si así puede decirse) del Hijo»" ${ }^{110}$. Supuesta esta afirmación y a partir de lo que Rahner considera la "única interpretación posible» del texto de Mt 27, 52s. que, añade, «ha encontrado siempre el consentimiento de una gran parte de los padres de la Iglesia y de los teólogos posteriores ${ }^{111}$, incluso gran parte de los citados en la Bula de la definición dogmática, existen otros hombres que ya han alcanzado la consumación total, es decir, la transfiguración corporal. «Está atestiguado como fe de la Escritura y de la Iglesia de los orígenes que la resurrección de un hombre ya realizada no es solo una posibilidad intrínseca garantizada por la resurrección de Cristo, sino en determinados casos un suceso real ya acontecido» ${ }^{12}$. Cuando la antigua Iglesia profesaba la creencia en el descendimiento de Cristo a los infiernos, pensaba también en otros muertos que ya ahora participan de la victoria definitiva y completa sobre la muerte y el pecado. Tal posibilidad convertida en realidad no es, estrictamente considerada, una anticipación de un suceso que propiamente y de manera normal recién ocurriría posteriormente, sino es el comienzo del fin. La consumación de la historia de la salvación ya ha comenzado. Y la asunción de María debe verse, afirma Rahner en su mariología, "como un pedazo, como una parte del comienzo de las realidades últimas del mundo», «un momento en el misterio cósmico de

109 Cf. «Das "neue” Dogma. Zur Definition der Himmelfahrt der hl. Jungfrau und Gottesmutter», en Sämtliche Werke. Bd. 9, 475- 495, 477 (original de 1950).

110 «Das "neue” Dogma», 478.

111 «Das "neue" Dogma», 479. Rahner ha recurrido frecuentemente a este texto bíblico. Cf., por ej., "Zum Sinn des Assumpta-Dogmas», en Sämtliche Werke. Bd. 9, 502-511, 505s. (original de 1951); "Assumptio Beatae Mariae Virginis», Sämtliche Werke. Bd. 9, 3-392, 52-53, 99, 100, nota 267, 205-209, 211, 213-214, 221, 307; "Zur konziliaren Mariologie», Stimmen der Zeit 174 (1964), 87-101, 94.

112 «Das "neue” Dogma», 479. 
«Entiendes de exégesis menos de lo deseable». La Escritura en la obra de Karl Rahner 137

Cristo. (...) El comienzo de la victoria en la transformación del mundo (como gracia recibida) no es "anónimo", sino que hoy puede ser llamado con un nombre: María» ${ }^{113}$. Recién en una entrevista de 1984, Rahner tomó distancia de esa interpretación del texto de Mt 27: hoy ya no puede interpretarse de esa manera, pero fue una idea interesante recurrir, con la opinión mayoritaria de los Padres de la Iglesia, a los resucitados salidos de sus tumbas; con ello se mostraba que una resurrección anticipada no era contraria a la Biblia (unbiblisch) ${ }^{114}$. Ahora bien, ¿es este un ejemplo de lo que Rahner ha criticado repetidamente en los manuales teológicos de su tiempo: la utilización «de un pasaje bíblico aislado como dicta probantia», en el que no es considerada «la Escritura como una totalidad», como "norma de nuestro hablar», sino que dicha cita bíblica «ha dado aprobación a una frase que en su verdad y sentido estaba fijada previamente» ${ }^{115}$. Esta pregunta debería analizarse junto a esta otra: la idea de la unidad del hombre, ¿depende en Rahner de la Escritura y su mentalidad o, en mayor medida, de un análisis detallado de la noción tomista de forma y materia prima?

Otro ámbito de investigación podría estar dado por el estudio del material utilizado al afrontar los diversos tratados teológicos en la enseñanza universitaria en Innsbruck (1937-1939; 1949-1964), Pullach (19451948) y Münster (1967-1971). Fundamentalmente Rahner desarrolló tres tratados: a) la doctrina de la gracia (De gratia Christi) ${ }^{116}$; b) la enseñanza sobre la penitencia, que incluyó algunas veces el sacramento de la unción y del orden (De poenitentia; De sacramentis II); c) la doctrina sobre la creación, la antropología y el pecado original (De Deo creante;

113 «Assumptio Beatae Mariae Virginis», 324.

114 Cf. Bekenntnisse. Rückblick auf 80 Jahre, G. Sporschill (ed.) (Wien 1984) 22. Para la interpretación de Rahner, y también de otros autores, tuvo relieve el artículo de $\mathrm{H}$. Zeller, «Corpora Sanctorum: Eine Studie zu Mt 27, 52-53», Zeitschrift für katholische Theologie 71 (1949), 385-465. Rahner afirma en "Assumptio Beatae Mariae Virginis», 205 nota 445, que se apoya en las investigaciones de dicho artículo, lo hace sin «miedo a plagio", porque a él se debe la sugerencia del tema y porque puso a disposición de Zeller «una buena parte del material» con que él trabaja.

115 Cf. «Schriftbeweis. II.», en Lexikon für Theologie und Kirche. Bd. 9 (Freiburg i.Br. $\left.{ }^{2} 1964\right), 486-487,487$.

116 La importancia del texto de $1937 / 38$ ha sido subrayada en época reciente de manera repetida. Cf. por ej., P. Rulands, " "Der Heilswille Gottes berührt uns in Christus Jesus und der Kirche”: Die erste Gnadenvorlesung», en A. Batlogg y otros, Der Denkweg Karl Rahners (Mainz 2003), 106-131. 
De Deo elevante et de peccato originali). La cristología recién la enseñó por primera vez en 1971 en Münster, al final de su carrera docente. Todavía algunos de estos materiales están inéditos ${ }^{117}$. Un juicio provisorio, necesitado de mayor verificación, puede adelantar que el trabajo bíblico explícito y el impacto de él en la producción teológica está lejos, todavía, de representar el «alma de la teología», en el espíritu de la formulación conciliar. El tratamiento bíblico está allí presentado como probatio de una tesis formulada ya previamente ${ }^{118}$. Aunque dichos textos no carecen de aspectos de relieve, sea para el análisis de la evolución del pensamiento rahneriano, sea para la historia de la teología católica en el siglo XX, en su estructura son prisioneros del esquema y selección del temario de los manuales de teología que Rahner critica frecuentemente ${ }^{119}$.

Un análisis más completo de la presencia y eficacia de la Biblia en la obra de Rahner debe prestar atención a un aspecto destacado en su obra. El mismo autor distingue entre escritos espirituales y filosófico-teológicos en su producción, más exactamente, entre «meditaciones "teológicas" en sentido estricto", "otras meditaciones orientadas más bien al ejercicio inmediato de la vida espiritual» y «obras teológicas de carácter escolar y

117 Karl Rahner. Sämtliche Werke. Bd. 8. Der Mensch in der Schöpfung (Düsseldorf - Freiburg i.Br. 1998), incluye el inédito: "Tractatus de Deo creante et elevante et de peccato originali», 41-511, con traducción alemana; Karl Rahner. Sämtliche Werke. Bd. 18. Leiblichkeit der Gnade: Schriften zur Sakramentenlehre (Freiburg i.Br. 2003) incluye el texto inédito: "De extrema uncione», 730-781; Karl Rahner. Sämtliche Werke. Bd. 6/1. De paenitentia: Dogmatische Vorlesungen zum Bußsakrament (Freiburg i.Br. 2007); Karl Rahner. Sämtliche Werke. Bd. 6/2. De paenitentia: Dogmatische Vorlesungen zum Bußsakrament (Freiburg i.Br. 2009) primera publicación de las clases.

118 En el caso del De Gratia Christi, el esquema que organiza cada tema: Thesis; I. Status quaestionis; II. Sensus Thesis; III. Adversarii; IV. Qualificatio; V. Probatio (Ecclesia, Scriptura, Patres, Theologi, Ratio Theologica). Cf. De Gratia Christi. Summa praelectionum in usum privatum auditorum ordinata (Oeniponte 1937/38) (inédito). Utilizo una reimpresión de 1956 de la tercera edición (1951), que tiene pocas diferencias con la primera, según el mismo Rahner en el Praefatio ad tertiam editionem. Un esquema análogo, casi idéntico se advierte en el texto "Tractatus de Deo creante et elevante et de peccato originali», recién citado, que se remonta a 1953. Aunque en este caso, el espacio dedicado a la Escritura es claramente más amplio y fundado. Cinco veces impartió Rahner este curso en Innsbruck, entre 1949 y 1962, y luego, con otro material, una vez en Münster (1967).

119 Cf., por ej., al inicio del mismo texto, «Tractatus de Deo creante et elevante et de peccato originali», 45 . 
técnico» ${ }^{120}$. Esta distinción se orienta, en el contexto concreto en que es formulada en 1966, a presentar y justificar la inclusión del primer grupo de textos en el volumen séptimo de los Schriften zur Theologie. Rahner cree que el trabajo y esfuerzo en este campo «no es menos teología que la investigación y la búsqueda en otras disciplinas». Una meditación puede «ser teología real y seria», en ella se pueden "tocar puntos esenciales que en las obras teológicas de carácter escolar y técnico o apenas son mencionados, o fueron olvidados, o no pueden ser formulados con la suficiente claridad y precisión» ${ }^{121}$. En una entrevista de 1974 reafirma su convicción, considera sus «meditaciones teológicas y espirituales» «no como un producto secundario marginal de una teología»; en ellas hay "por lo menos tanta teología» como "en las así llamadas obras científicas» ${ }^{122}$. No pocos autores han subrayado la importancia de esta advertencia para una comprensión más completa y exacta de la obra de Rahner. Por tanto, debería atenderse a este campo de trabajo, iniciando el itinerario, ante todo, por el primer libro publicado por Rahner en 1938 y, particularmente, por el más exitoso de toda su producción en términos de venta y difusión de $1949^{123}$. En el marco de este análisis habría que incluir la importante bibliografía en torno al acontecimiento del año litúrgico, meditaciones $y$, particularmente, homilias, vinculadas a tiempos litúrgicos y a festividades diversas, cuyas publicaciones se extienden a lo largo de toda la vida de Rahner ${ }^{124}$. Su estudio más detallado, desde esta perspectiva, permitiría apreciar el arraigo de Rahner en la cotidiana tradición de la lectura bíblica eclesial. Vinculado a este aspecto, pero diferente de él, deberían considerarse las reflexiones sobre el «servicio a la Palabra» como "primera función fundamental de la Iglesia» que Rahner tematiza en el contexto de su tratamiento de la teología práctica o pastoral ${ }^{125}$.

120 Schriften zur Theologie. Bd. 7. Zur Theologie des geistlichen Lebens (Einsiedeln 1966), 7.

121 Ibid., 7.

122 «Gnade als Mitte menschlicher Existenz», 81.

123 Worte ins Schweigen (Innsbruck 1938); Von der Not und dem Segen des Gebetes (Innsbruck 1949). Ambos tienen muchas ediciones y, también, traducción castellana. Sobre la importancia del primer texto, cf. K. Neufeld, "Worte ins Schweigen. Zum erfahrenen Gottesverständnis Karl Rahners», Zeitschrift für katholische Theologie 112 (1990), 427-436.

${ }^{124}$ La edición más amplia es la de 1986: Das große Kirchenjahr. Geistliche Texte, editada por A. Raffelt (Freiburg i.Br. 1986). Contiene 120 meditaciones y predicaciones.

125 "Die Verkündigung des Wortes», en Handbuch der Pastoraltheologie. Bd. 1 (Freiburg i.Br. 1964), 219-229 (ahora en Sämtliche Werke. Bd. 19, 151-160). Sobre 
En el prólogo al volumen duodécimo de los Schriften zur Theologie, Rahner reconoce que para el conjunto de su teología la experiencia del Espíritu es un fundamento que posee una significación decisiva. Más aún, concretiza esa experiencia como «aquella experiencia específica a la cual Ignacio de Loyola, mediante los Ejercicios Espirituales quiso enseñar y conducir» y expresa el "hecho histórico de que su propio teologizar parte de la experiencia de los Ejercicios ignacianos» ${ }^{126}$. De hecho, Rahner calificó a un célebre texto suyo sobre Ignacio como una «suerte de testamento", o "resumen de mi teología y de aquello que yo intenté vivir» ${ }^{127}$. Esta perspectiva de acceso a la obra de Rahner, largamente olvidada, ha adquirido un relieve cada vez mayor en los últimos años. Probablemente, el mejor trabajo hoy existente en esta línea corresponde a A. Zahlauer, sin olvidar el de P. Endean ${ }^{128}$. Con ella fructifica una línea de investigación que tiene sus principales fundamentos en los excelentes trabajos de K. Fischer ${ }^{129}$ y N. Schwerdtfeger ${ }^{130}$ y en las repetidas observaciones de K. Neufeld. Zahlauer estudia la historia de la formación del pensamiento rahneriano a partir del impulso ignaciano. El núcleo de su obra muestra cómo se convierte y transforma una experiencia espiritual en un pensamiento teológico sistemático. De allí el título del trabajo de Zahlauer: «Karl Rahner y su "modelo ejemplar" Ignacio de Loyola»"

dicha teología, cf. A. Vigueras, «La teología práctica de Karl Rahner. Una teología pastoral en perspectiva escatológica», Teología y Vida 51 (2010), 445-476; A. LAUMER, Karl Rahner und die Praktische Theologie (Würzburg 2010).

126 «Vorwort», en Schriften zur Theologie. Bd. 12, 8 (cursiva mía). Cf., también, K. H. Neufeld, «Karl Rahner. Theologie als Sprechen vom Geheimnis Gottes» en J. BrosSEDER (ed.), Dialogfähige Theologie (Hamburg - Neukirchen -Vluyn 1998), 133-149.

127 Glaube in winterlicher Zeit (Düsseldorf 1986), 128. Cf., también, Bekenntnisse. Rückblick auf80 Jahre (Wien 1984), 58. Refiere al texto «Rede des Ignatius von Loyola an einen Jesuiten von heute», en K. Rahner y otros, Ignatius von Loyola (Freiburg i.Br. 1978), 9-38 (recogido en Schriften zur Theologie. Bd. 15, 373-408 y, finalmente, en Sämtliche Werke. Bd. 25, 299-329).

128 Karl Rahner and Ignatian Spirituality (Oxford 2001).

129 Der Mensch als Geheimnis. Die Anthropologie Karl Rahners (Freiburg i.Br. 1974).

130 Gnade und Welt. Zum Grundgefüge von Karl Rahners Theorie der "anonymen Christen” (Freiburg i.Br. 1982).

131 Karl Rahner und sein "produktives Vorbild» Ignatius von Loyola (Innsbruck 1996). La expresión produktives Vorbild, que para Zahlauer constituye el concepto hermenéutico clave para la recepción ignaciana de Rahner, la emplea el mismo teólogo alemán en: «Ignatius von Loyola. Zur Aktualität des Heiligen», Geist und Leben 57 (1984), 337-340, 337. 
«Entiendes de exégesis menos de lo deseable». La Escritura en la obra de Karl Rahner | 141

En esta línea de trabajo deben valorarse, al menos, dos sentidos. Primero, el significado que tiene para la estructura de una personalidad humano-espiritual el contacto cotidiano con la Escritura dada su filiación espiritual. Y cómo esa experiencia luego se articula teológicamente y en torno a qué determinados núcleos evangélicos. Segundo, la importancia que algunos autores han otorgado recientemente a sus trabajos referidos a la temática de los «misterios de la vida de Jesús» como acceso a su fe cristológica y, desde esta perspectiva, arraigada en la Escritura ${ }^{132}$.

Es difundida la idea de la ausencia del tema veterotestamentario en la obra de Rahner. Más de lo que se cree, existe una lista de temas en Rahner en los cuales afronta con diversa extensión temáticas del AT: monogenismo, pecado en general y pecado original en particular, muerte, manifestación de lo profético, diversos aspectos de los sacramentos (como la esencia de la penitencia), la idea de creación en general, etc. Probablemente el artículo de 1967 es el más útil como conjunto: Rahner resume su propia perspectiva allí, con una explicación histórico-salvífica, muy próxima a la terminología del Vaticano II y prestando atención también a la salvación y revelación, más allá del mundo bíblico ${ }^{133}$. Sin contradecir la afirmación inicial, un análisis debería concretarse en orden a una justa respuesta al asunto.

132 En esta perspectiva es hoy fundamental el trabajo de A. Batlogg, Die Mysterien des Lebens Jesu bei Karl Rahner. Zugang zum Christusglauben (Innsbruck 2001). Para el tema en Rahner, además de los capítulos respectivos en la Cristología de 1972 y en el Gundkurs des Glaubens, debe atenderse a los textos de los ejercicios que predicó en la década del 50 y 60: «Mysterien des Lebens Jesu», en Lexikon für Theologie und Kirche. Bd. 7 (Freiburg i.Br. 1962), 721-722; "Bemerkungen zur Bedeutung der Geschichte Jesu für die Katholische Dogmatik», en G. Bornkam - K. Rahner (eds.), Die Zeit Jesu (Freiburg i.Br. 1970), 273-283 [recogido en Schriften zur Theologie. Bd. 10 (Zürich 1972), 215-226]; Betrachtungen zum ignatianischen Exerzitienbuch (München 1965), recogido ahora en Sämtliche Werke. Bd. 13, 37-265; Einübung priesterlicher Existenz (Freiburg i.Br. 1970), ahora recogido en Sämtliche Werke. Bd. 13, 269-437. Un ejemplo del análisis de textos bíblicos por parte de Rahner en relación a los ejercicios ignacianos, puede verse en A. ZaHLAUER, Karl Rahner und sein "produktives Vorbild", 86ss.

133 Cf. "Altes Testament. I. Heilsgeschichtlich» en Sacramentum mundi. Bd. 1 (Freiburg i.Br. 1967), 101-108; Cf., también, «Altes Testament (als heilsgeschichtliche Periode) I.», en Lexikon für Theologie und Kirche. Bd. 1 (Freiburg i.Br. 1957), 389393 y, particularmente, "Altes Testament und christliche Dogmatik», en Schriften zur Theologie. Bd. 12, 224-240. Sobre esta observación, cf. K. H. Neufeld, «Die Schrift in der Theologie Karl Rahners», 243. 


\section{REFLEXIONES FINALES - A MODO DE CONCLUSIONES}

Al final de este recorrido, y sin repetir las evaluaciones hechas en cada punto, pueden formularse algunas conclusiones provisorias.

1. «Intenté desentrañar el poder y el dinamismo interno que están ocultos en la teología escolástica», tal una descripción de su labor como teólogo. Ya a fines de la década del 30 muestra conciencia de que solo una renovación a partir de las propias raíces, y no por la confrontación con un sistema diverso, original, haría progresar la tradición filosóficateológica ${ }^{134}$. Desde este punto de vista, Rahner es en el siglo XX un autor protagónico clave, internacional, en la puesta en crisis de una determinada manera de hacer y enseñar teología, cuyo fin, puede verse simbólicamente en los primeros debates conciliares sobre el depósito de la fe y, en particular, de la revelación y la Escritura.

2. Aunque su contribución al Concilio se concreta ante todo en las cuestiones eclesiológicas, hemos corroborado su activa participación en algunas de las principales discusiones referidas a la Escritura ${ }^{135}$. Su aporte o influencia en la formulación de nociones fundamentales no puede desconocerse, piénsese, por ejemplo, en la de la misma revelación, no como locutio, sino como communicatio. Sus posiciones bíblico-sistemáticas, previas al Concilio, se direccionan en el sentido de este, de la posteriormente llamada mayoría conciliar.

3. Un punto destacado de su contribución es el intento de una explicación plausible de la vinculación intrínseca entre Escritura e Iglesia. Esto ha podido constatarse claramente sea en la propuesta sobre la noción de inspiración, sea en los debates sobre la relación entre la Escritura y la Tradición. La Escritura es pensada como un momento constitutivo y normativo para el futuro del devenir de la Iglesia misma, en tanto historización de la voluntad salvífica universal, esto es de la autocomunicación de Dios a toda creatura, en conexión con la imagen de $E$ latere Christi de los primeros años de su producción teológica. La importancia de este trabajo eclesiológico bíblico-patrístico no puede ser minusvalorado, particularmente en atención al modelo eclesiológico existente en-

134 Cf. "Begleittext zu "Geist in Welt"» en Sämtliche Werke. Bd 2, 431-437.

135 Cf. C. Schickendantz, «Escritura y Tradición. Karl Rahner en el "primer conflicto doctrinal” del Vaticano II», Teología 106 (2011) en edición. 
«Entiendes de exégesis menos de lo deseable». La Escritura en la obra de Karl Rahner | 143

tonces, radicalmente diferente: un modelo institucional de Iglesia como societas perfecta ${ }^{136}$.

4. En varias cuestiones discutidas del momento, Rahner representa un cierto equilibrio o posición intermedia. Expresado de una manera simple: en las discusiones inmediatamente anteriores al Concilio toma partido por la posición del Biblicum, valorizando el uso del método histórico-crítico en los estudios bíblicos, pero a eso se añade, por una parte, su reclamo a que la exégesis se autocomprenda como disciplina teológica y, por otra, que la relación entre Escritura, Tradición e Iglesia (y magisterio) resulte intrínsecamente explicada y no solo como una adición yuxtapuesta de realidades independientes. Esta última es, quizás, la preocupación magisterial más importante de los últimos años en el área bíblica, según mi parecer, que puede encontrar una expresión sintomática en las reiteradas afirmaciones e iniciativas del entonces cardenal J. Ratzinger.

5. Como hemos constatado, es posible encontrar críticas agudas a la utilización de la Biblia en la dogmática de manuales ya en textos rahnerianos de inicios de la década del 40: el tratado de De Deo uno al uso, observa Rahner, "que en la mayoría de los casos son mera filosofía adornados con un poco de Escritura» ${ }^{137}$. No obstante, algunas observaciones del biblista W. Thüsing, fruto del experimento concretado conjuntamente en 1971/72, parece que pueden dirigirse, como crítica o insuficiencia, a la misma obra de Rahner: ¿̨hasta qué punto no está activo todavía en distintos lugares de dicha obra el esquema de los dicta probantia, que, por otra parte, Rahner clara y repetidamente rechaza como metodología adecuada? De manera análoga, puede formularse la pregunta de si el texto bíblico ocupa el lugar central que le corresponde o si ejerce el influjo que debiera o si se es consciente de las ventajas que se producirían si uno se introdujera, como ejemplifica Thüsing, «en la mentalidad de Pablo, con el mismo interés con que incorporamos a ciertas concepciones teológicas importantes de nuestro tiempo»" ${ }^{138}$. Desde esta perspectiva surgirían, a no dudarlo, nuevos impulsos. El «modo de

136 Cf. A. Dulles, Models of the Church (New York $\left.{ }^{5} 2002\right), 26 s s$.

137 «Theos im Neuen Testament», 346 nota 1.

138 W. Thüsing, «Datos del Nuevo Testamento para una cristología trascendentaldialógica», en W. ThüsIng - K. Rahner, Cristología. Estudio teológico y exégetico, 83-299, 99. 
trabajo teológico» rahneriano, bíblico-patrístico, de los primeros años, no encuentra continuidad posteriormente. Constataciones de E. Maurice, aunque ella las refiere solo a la cristología, parecen acertadas como juicio más global: hay un progresivo «eclipse en la utilización de la Escritura", una "presencia implícita", siendo que una mayor utilización de ella "habría enriquecido» la reflexión ${ }^{139}$. El importante texto de 1942/43 sobre "Theos en el Nuevo Testamento", aunque indudablemente tiene una vinculación estrecha con la temática de Dios y ha debido ejercer su influjo en la elaboración de categorías rahnerianas centrales tales como autocomunicación o misterio (relación que Rahner no explicita) constituye una «excepción» en su labor teológica.

6. Como ha sido constatado en nuestro itinerario, la teología de Rahner se ha elaborado en una relación directa con las diversas demandas que se le presentaban. En este sentido es una teología situada, vinculada a momentos eclesiales, inquietudes personales o discusiones teóricas del momento. Ello explica, en buena medida, su carácter fragmentario, también su dispersión editorial. En esta línea, y en aplicación también al tema de la Escritura en su obra, concluyo con una observación de Rahner contenida en su última conferencia pública, en febrero de 1984, semanas antes de su muerte:

Naturalmente sé que en mi teología hay quizás un número considerable de elementos que no concuerdan clara e inequívocamente, puesto que un hombre, dado el pluralismo original de las fuentes de su conocimiento, no está en condiciones de llevar a cabo una reflexión adecuada y abarcativa sobre la coherencia de sus afirmaciones. De allí que un teólogo pueda pedir a sus amigos y a sus adversarios que se aproximen a su teología con una indulgente buena voluntad y que consideren más importantes sus puntos de partida, tendencias fundamentales y planteamientos que los "resultados", que, al fin y al cabo, no pueden ser nunca realmente definitivos ${ }^{140}$.

139 Cf. E. Maurice, La christologie de Karl Rahner, 242-243.

140 "Erfahrungen eines katholischen Theologen», en K. LeHmann (ed.), Vor dem Geheimnis Gottes den Menschen verstehen. Karl Rahner zum 80. Geburtstag (München 1984), 105-119, recogido en Sämtliche Werke. Bd. 25, 47-57. Citada aquí según la traducción de C. Schickendantz, en Proyecto 42 (2002) 7-20, 16. 
«Entiendes de exégesis menos de lo deseable». La Escritura en la obra de Karl Rahner | 145

Resumen: Es conocida la crítica a la teología de Karl Rahner según la cual la Biblia no encuentra allí su lugar fundante como alma de la teología. Se trataría de un sistema especulativo con poco trabajo bíblico e histórico. El artículo ofrece un panorama en orden genético que analiza los principales trabajos de Rahner sobre el asunto. Considera de particular relieve, lo que, hacia el final del artículo, se titula como "ámbitos o perspectivas ulteriores de trabajo", algunos de ellos tan importantes para una adecuada comprensión de Rahner. El itinerario revela los múltiples matices necesarios para evaluar la crítica aludida.

Palabras clave: Tradición, Vaticano II, Dei Verbum, inspiración.

Abstract: Karl Rahner's well-known critique to theology states that the Bible is not the founding source of theology. It is rather a speculative system with little biblical and historical work. The article offers a genetic overview which analyzes Rahner's main works on the subject. It is considered of particular importance, what towards the end of the article is titled "ulterior areas or perspectives of work", some of which so important for an adequate understanding of Rahner. The itinerary reveals the multiple nuances required to assess the aforementioned critique.

Keywords: Tradition, Vatican II, Dei Verbum, inspiration. 